\title{
Work Stress and Job Satisfaction among Nursing Staff in Public Hospitals in Nigeria
}

\section{Omole Iyayi and Alasa Paul Kadiri*}

Department of Business Administration, Faculty of Management

Sciences, University of Benin, Nigeria

\section{Abstract}

Stress is an everyday reality regardless of occupation or profession. In the past decades, work-related stress has become a major source of health-related issues among workers in organizations around the globe. Numerous research studies have examined this biological phenomenon given its negative consequences on employees' wellbeing, and threat to organizational survival and competitiveness. Job satisfaction is a key work attitude that is highly desirable in the workplace if organizational goals and objectives are to be achieved. This study investigated the relationship between work stress and job satisfaction among nursing staff in selected public hospitals in Benin City, Edo State, Nigeria. The dimensions of work stress examined include role ambiguity, role conflict, job overload, poor social support, and poor work environment. A cross-sectional survey research design was adopted for the study. Three hundred and five $(n=305)$ nurses in public hospitals in Benin City were selected for the study. Data generated for the study were analyzed with ordinary least squares regression techniques. The results indicated that except for role ambiguity, other work stressors investigated, which are role conflict, job overload, poor social support, and poor work environment, had a significant and negative relationship with job satisfaction of nurses. It was recommended that more nurses should be employed in public

*Corresponding should be addressed to Dr Alasa Paul Kadiri, Department of Business Administration, Faculty of Management Sciences, University of Benin, Nigeria

Email: alasa.kadiri@uniben.edu

https://orcid.org/0000-0003-3316-8160

(Received 2nd June 2020; Revised 25th October 2020; Accepted 30th October 2020 (C) OUSL) 
hospitals in Nigeria, and that management of public hospitals in Nigeria should ensure that the physical work environment is conducive for nurses to perform their job tasks and responsibilities.

Keywords: Hospitals, Job satisfaction, Nurses, Public hospitals, Work stress

\section{Introduction}

Stress is an everyday reality that is experienced by everyone regardless of gender, age, religion, or nationality (Kadiri \& Akinmayowa, 2015; Radhakrishnan, 2013). Work stress is the mismatch between the expectations or requirements of the job and resources available to meet these requirements or expectations (Kadiri \& Akinmayowa, 2015). Work-related stress could have severe consequences for employees' well-being if left unattended to. For instance, work stress could trigger depression (Adegoke, 2014), burnout, and fatigue in employees (Ojekou \& Dorothy, 2015). Further, work-related stress could stimulate emotional wear and tear in employees, which may further manifest in decreased productivity, lowered employee commitment, and job satisfaction (Gulavani \& Shinde, 2014).

Job satisfaction is the optimistic feelings an employee has about various aspects of his or her job or work situation (Hans, Mubeen, Khan \& Al Saadi, 2014; Spector, 1997). The importance of a satisfied workforce cannot be overemphasized. For instance, organizational participants that derive satisfaction from their jobs are more likely to be highly involved and committed to the organization than employees that are dissatisfied with their jobs. Other benefits of a satisfied workforce include reduced absenteeism, a high level of organizational trust, and the likelihood of organizational members engaging in creative work performance which have been theorized to be key to organizational competitiveness, profitability, and survival (Bokti \& Talib, 2009).

Evidence from extant literature indicates that workers in the public sector in Nigeria of which the health sector is no exception, no longer experience low-stress work environment that they once did due 
mainly to maladministration, poor conditions of work, mismanagement, and high level of corruption (Ogungbamila \& Fajemirokun, 2016; Kadiri \& Akinmayowa, 2015; Ogungbamila, 2013). Over the years, work-related stress has emerged as a major challenge faced by health officials in Nigeria hospitals. While the consequences of work-related stress have been well documented in the extant literature, it links with nurses' job satisfaction in Nigeria is yet to be fully known to the best of the researchers' knowledge. Moreover, empirical studies revealed mixed findings as it pertains to the link between work stress and employees' job satisfaction. For instance, while Yaacob and Long (2015) found a positive relationship between work stress and job satisfaction, Mathew (2013) found a negative relationship between work stress and job satisfaction among nurses. These contradicting findings need further verification. The objective of this study, therefore, is to examine the relationship between work stressors, decomposed into role ambiguity, role conflict, job overload, poor social support and poor physical work environment and job satisfaction among nurses in public hospitals in Benin City, Edo State, Nigeria.

\section{Review of Literature}

\section{Concept of Job Satisfaction}

From a general perspective, job satisfaction describes the overall wellbeing of an employee in terms of the different work-related issues which affect an individual's quality of work-life (Gulavani \& Shinde, 2014). In a similar vein, job satisfaction is a multi-dimensional concept and as such, is explained from different perspectives depending on the orientation of the author(s). For example, Essiam, Mensah, Kudu and Gyamfi (2015) described job satisfaction as employees' reactions towards their work experiences. Venkataraman and Ganapathi (2013) explained job satisfaction as an emotional reaction to one's job. According to Spector (1997) job satisfaction is the positive feeling employees have about their jobs. Similarly, job satisfaction is defined as a positive feeling employee have about their work situations (Hans et al., 2014). Numerous determinants of job satisfaction have been identified in the extant literature. However, the 
determinants of job satisfaction have been categorized into two broad factors namely: extrinsic factors and intrinsic factors. Extrinsic factors include salary, supervision, workload, working conditions, interpersonal relationship, and work schedule. Intrinsic factors consist of achievement, feedback, job security, value of work, accepting responsibility, and cooperation across departments.

\section{Concept of Work Stress}

Sinha, Chatterjee and Iskanius (2011) defined work stress as the negative feeling that employees have when they are uncomfortable or irritated in their work environment such that it reduces their interest in the job. Also, work stress is defined as the mismatch between the expectations or requirements of the job and resources available to meet these requirements or expectations (Kadiri \& Akinmayowa, 2015). In a similar vein, Ogungbamila (2013) posited that work stress is the mismatch between the expectations of the job and the requisite skills or experience needed to cope with these expectations. From the foregoing, we define work stress as the physiological, psychological, and behavioural response of employees to work demands which may have harmful or behavioural consequences.

In the extant literature, different forms, types, and levels of stress have been identified. The most common ones according to Gupta, Gupta, Mishra and Sharma (2011) are eustress and distress. Eustress also referred to as positive stress, is the type of stress which occurs when employees react or respond positively to work conditions, events, and circumstances in their workplace or work environment. It usually manifests in the form of thrills and excitements, which may be predisposed by the offering of awards or prizes, a recommendation for an increase in salary, promotion, and challenging job (Folkman \& Lazarus, 1984). Elucidating on this, eustress is usually short but exerts a healthy effect (Gupta et al., 2011). It stimulates energy among employees which help them to generate optimum output by putting more effort into their work performances (Shinde \& Mane, 2014). Distress, also referred to as negative stress is usually triggered by a reaction to troubled events which include the death of loved ones, sickness, financial crisis, heavy workload, work-family conflict, sack, job insecurity, and unemployment (Gupta et al., 2011). Distress can be categorized into 
two types, which are acute stress and chronic stress. While acute stress comes quickly on the individual and oftentimes throws him off balance, chronic stress tends to occur regularly. The difference between acute stress and chronic stress is the intensity of the reactions to stress. This is because acute stress is often short-term, and it is usually triggered by a loss of contract, documents as well as thinking of recent past events and anticipation of future job demands (Ogungbamila, 2013). Chronic stress, on the other hand, may leave the individual feeling drained and might result in burnout if it is not properly and effectively managed. When triggers, stress can lead to psychological distress, tension, headaches, stomach upset, and other symptoms (Sinha, Chatterjee \& Iskanius, 2011). Several factors can induce stress in employees in the workplace. These factors include an unhealthy work environment, inadequate support from management or unit/department heads, role ambiguity, role conflict, poor social support at work, and job overload (Ogungbamila, 2013). Examining the relationship between work-related stress and job satisfaction among university teachers, Siddique and Farooqi (2014) did not establish any link between the variables. A similar study by Gulavani and Shinde (2014) did not find any link between workrelated stress and job satisfaction among nurses. Mardhiah and Choi (2015) investigated the relationship between job stress and job satisfaction among teachers and found that there is a significant negative relationship between the variables. They specifically demonstrated that role ambiguity had a significant but negative relationship with job satisfaction.

\section{Theoretical Framework}

This study adopts the conservation of resources theory as developed by Hobfoll (1989). According to this theory, stress occurs when available resources are insufficient to execute work tasks, when the available resources are threatened or when people invest their resources without substantial gain (Hobfoll, 1989). Matthew (2013) posited that when employees are given too much workload with little available time or resources to perform the given task(s) work-related stress occurs. According to Gulavani and Shinde (2014), poor resources or inadequate resources could result in job dissatisfaction. Locke (1976) notes that the withholding of resources to perform the 
job has been recognized as one of the greatest factors eliciting negative feelings among employees.

Figure 1 shows the research model. Specifically, the parameters of the model which include job overload, role ambiguity, role conflict, social support, and physical work environment are proposed as work stressors which may impact job satisfaction of nurses. The researchers intend to empirically verify the relationship that exists between these work stressors and job satisfaction.

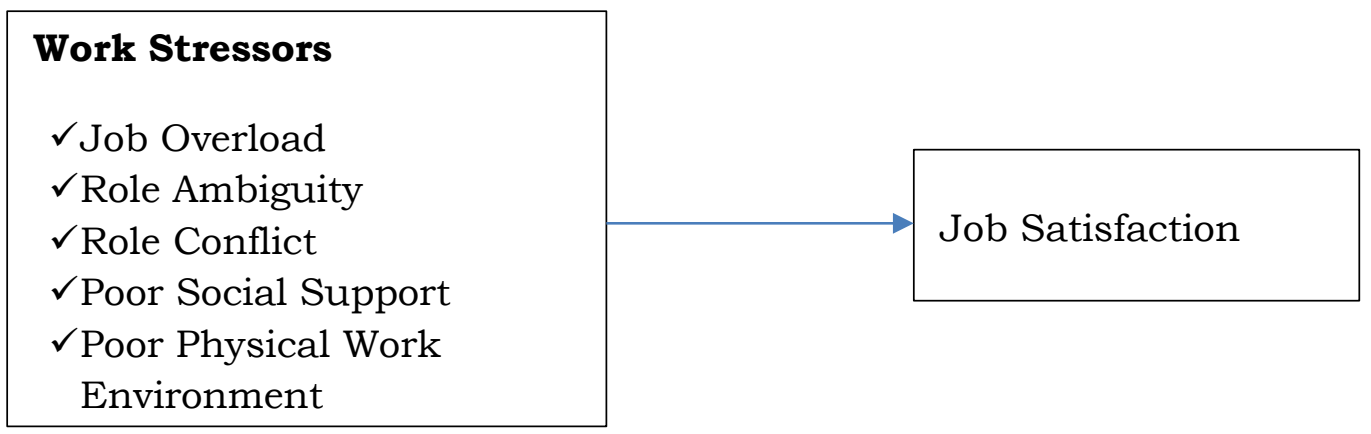

Figure 1: The Conceptual Framework

\section{Research Hypotheses}

The following hypotheses which were stated in their null forms were tested in the study.

$\mathrm{H}_{01}$ : There is no significant relationship between job overload and job satisfaction of nurses in public hospitals in Benin City.

$\mathrm{H}_{02}$ : There is no significant relationship between role ambiguity and job satisfaction of nurses in public hospitals in Benin City.

$\mathrm{H}_{03}$ : There is no significant relationship between role conflict and job satisfaction of nurses in public hospitals in Benin City.

$\mathrm{H}_{04}$ : There is no significant relationship between poor physical work environment and job satisfaction of nurses in public hospitals in Benin City.

$\mathrm{H}_{05}$ : There is no significant relationship between poor social 
support and job satisfaction of nurses in public hospitals in Benin City.

\section{Methodology}

A cross-sectional survey research design was adopted for the study. Using a population of 987, 226, and 68 nurses respectively for the University of Benin Teaching Hospital, Central Hospital, and Stella Obasanjo Hospital, the study's population comprised 1281 nurses in the selected public hospitals in Benin City, Edo State. Since the population is known, Yamane (1967) statistical formula was used to determine the sample size for the study. The formula is given as follows:

$$
\mathrm{n}=\frac{N}{1+N(e)^{2}}
$$

Where: $\mathrm{n}=$ Sample size, 1 =Constant value, $\mathrm{N}=$ Population size, e = Level of precision or acceptable sample error (0.05).

$\mathrm{n}=\frac{1281}{1+(0.05)^{2}}=304.82$

Hence, a sample size of approximately 305 nurses was involved in the study. Furthermore, a proportional allocation formula was used to ensure a proportionate survey of the 305 respondents across the three hospitals in Benin City. The formula is given as;

$$
\mathrm{n}_{\mathrm{h}}=\frac{N h_{\times}}{N} \mathrm{n}
$$

Where:

$\mathrm{n}_{\mathrm{h}}=$ sample size for stratum $h ; \mathrm{Nh}=$ population size for stratum $h ; \mathrm{N}$ $=$ total population.

The formula was applied as follows: 
UBTH: $\mathrm{n}_{\mathrm{h}}=\frac{987}{1281} \times 305=235$

Central Hospital: $\mathrm{nh}=\frac{226}{1281} \times 305=54$

Central Hospital: $\mathrm{nh}=\frac{68}{1281} \times 305=16$

This means that 235, 54, and 16 nurses in UBTH, Central Hospital, and Stella Obasanjo Hospital were surveyed respectively. However, to minimize the low response rate, the sample size was increased by $10 \%$ for each of the hospitals, bringing the sample size to 258,59 , and 18 respondents for UBTH, Central Hospital, and Stella Obasanjo Hospital respectively. Out of 335 questionnaires that were proportionally distributed to respondents in the three hospitals, 235, 54 , and 16 questionnaires were returned and found useful for data analysis for UBTH, Central Hospital, and Stella Obasanjo Hospital respectively.

The questionnaire was divided into sections A and B. Section A contained questions eliciting information on respondents' demographic variables. Section B contains questions measuring work stress and job satisfaction. A 24-items research instrument tagged "Nurses Job Stress Scale" (NJSS) was used to measure job stressors. The job stressors measured were job overload, role ambiguity, role conflict, physical work environment, and social support. Items on the scale were validated by three senior academics in the Faculty of Management Sciences, University of Benin, Nigeria. A pilot test was carried out among 50 nurses spread across the sampled public hospitals in other to confirm the reliability of the scale. The selected respondents were not part of the sampled respondents. Job satisfaction was measured using Macdonald and MacIntyre (1997) 10-item scale. 
Table 1.

Reliability Scores for the Variables of the Study

\begin{tabular}{|c|c|c|c|c|}
\hline \multirow[t]{3}{*}{ Construct } & \multirow{3}{*}{\multicolumn{2}{|c|}{ Sub-constructs }} & Numbe & Cronbach' \\
\hline & & & $\mathbf{r}$ of & s Alpha \\
\hline & & & Items & Value \\
\hline \multirow[t]{5}{*}{ Job Stressors } & Job overload & & 6 & 0.751 \\
\hline & Role ambiguity & & 4 & 0.812 \\
\hline & Role conflict & & 5 & 0.875 \\
\hline & $\begin{array}{l}\text { Physical } \\
\text { environment }\end{array}$ & work & 5 & 0.711 \\
\hline & Social support & & 4 & 0.778 \\
\hline $\mathrm{Job}$ & & & 10 & 0.770 \\
\hline Satisfaction & & & & \\
\hline
\end{tabular}

The reliability examined for each scale is shown in Table 1 . The scales were rated with a 5-point Likert scale using the anchors: $1=$ strongly disagreed, $2=$ disagreed, $3=$ not sure, $4=$ agreed, and $5=$ strongly agreed.

To examine the relationship between work stress and job satisfaction, the study employed the following model.

$\mathrm{JSN}=f(\mathrm{JOV}, \mathrm{JAB}, \mathrm{RCO}, \mathrm{PEN}, \mathrm{PSS})$

In this study, the regression model is specified as follow:

$\mathrm{JSN}_{\mathrm{t}}=\beta_{0}+\beta_{1} \mathrm{JOV}+\beta_{2} \mathrm{JAB}+\beta_{3} \mathrm{RCO}+\beta_{4} \mathrm{PPE}+\beta_{4} \mathrm{PSS}+\mathrm{e}_{\mathrm{t}}$

Where:

$\begin{array}{lll}\mathrm{JSN} & = & \text { Job satisfaction of nurses } \\ \mathrm{JOV} & = & \text { Job overload } \\ \mathrm{RAB} & = & \text { Role ambiguity } \\ \mathrm{RCO} & = & \text { Role conflict } \\ \mathrm{PPE} & = & \text { Poor physical work environment }\end{array}$




$\begin{array}{lll}\text { PSS } & = & \text { Poor social support } \\ \beta_{0} & = & \text { constant } \\ \beta_{1} \ldots \beta_{5} & = & \text { coefficients of the independent variables } \\ e_{t} & = & \text { Error term at time } \mathrm{t} .\end{array}$

The Apriori expectations for our variables are $\beta_{1}, \beta_{2}, \beta_{3}, \beta_{4}, \beta_{5} t<0$. This indicates that all the independent variables are expected to have negative relationships with job satisfaction, which is our dependent variable. Simple percentage, mean, and ordinary least square (OLS) regression technique was used for data analysis. All tests were conducted at $\mathrm{a}=0.05$ using Eview version 8.0.

\section{Results and Discussion}

\section{Demographic Characteristics of the Participants}

A descriptive analysis of the demographic information of respondents was undertaken in this section.

Table 2.

\section{Demographic Characteristics of the Participants}

\begin{tabular}{llll}
\hline Variables & $\begin{array}{l}\text { Respondents' } \\
\text { Category }\end{array}$ & $\begin{array}{l}\text { Frequency } \\
\text { (N=302) }\end{array}$ & $\begin{array}{l}\text { Percentage } \\
\text { (\%) }\end{array}$ \\
\hline \multirow{2}{*}{ Gender } & Male & 141 & 47.0 \\
& Female & 161 & 53.0 \\
& Under 25 & 70 & 23.4 \\
Age (years) & $25-35$ & 101 & 33.3 \\
& $36-45$ & 69 & 22.8 \\
& $46 a n d$ above & 62 & 20.5 \\
Marital status & Single & 72 & 23.8 \\
& Married & 225 & 74.5 \\
Length of & Separated/Divorced & 5 & 1.7 \\
(years) & 0-5 & 60 & 19.8 \\
Educational & 6-10 & 195 & 64.6 \\
& 11 and more & 47 & 15.6 \\
& NCE/Diploma/OND or & 42 & 13.9
\end{tabular}


qualifications

Equivalent

$\begin{array}{llll}\text { HND /B.Sc. } & \text { or } & 156 & 51.6 \\ \text { Equivalent } & & & 31.1 \\ \text { M.Sc or Equivalent } & 94 & 3.4 \\ \text { Ph.D. or Equivalent } & & 10 & \end{array}$

Key: NCE: National Certificate Examination; OND: Ordinary National Diploma; HND: Higher National Diploma

Table 2 shows that out of 305 questionnaires that were distributed to respondents, 302 questionnaires were returned and found useful for data analysis. Table 2 revealed that the majority of the respondents were females. This accounted for $53 \%(n=161)$ of the total respondents. Table 2 also revealed that the majority of the respondents were aged $25-35$ years $(n=101,33.3 \%)$; married $(n=225$, $74.5 \%)$; spent 6-10years $(n=195,64.6 \%)$; and have HND/B.Sc degree $(\mathrm{n}=156,51.6 \%)$.

\section{Univariate and Correlational Analyses of Work Stressors and Job Satisfaction}

Pearson correlation analysis was conducted to establish the relationship among the study's variables. The results are shown in Table 3.

Table 3. Mean, Standard Deviation and Pearson Correlation between Work Stressors and Job Satisfaction

\begin{tabular}{|l|l|l|l|l|l|l|}
\hline \multicolumn{1}{|c|}{ Variable } & \multicolumn{1}{c|}{$\mathbf{1}$} & \multicolumn{1}{c|}{$\mathbf{2}$} & \multicolumn{1}{c|}{$\mathbf{3}$} & \multicolumn{1}{c|}{$\mathbf{4}$} & \multicolumn{1}{c|}{$\mathbf{5}$} & \multicolumn{1}{c|}{$\mathbf{6}$} \\
\hline Job Satisfaction & 1 & $-0.509^{* *}$ & $-0.163^{* *}$ & -0.086 & $-0.548^{* *}$ & $-0.384^{* *}$ \\
\hline Role Conflict & $-0.509^{* *}$ & 1 & $0.403^{* *}$ & $0.272^{* *}$ & $0.675^{* *}$ & $0.518^{* *}$ \\
\hline $\begin{array}{l}\text { Poor Physical Work } \\
\text { Environment }\end{array}$ & $-0.163^{* *}$ & $0.403^{* *}$ & 1 & $0.118^{*}$ & $0.277^{* *}$ & $0.577^{* *}$ \\
\hline Role Ambiguity & -0.086 & $0.272^{* *}$ & $0.118^{*}$ & 1 & $0.244^{* *}$ & $0.150^{* *}$ \\
\hline Job Overload & $-0.548^{* *}$ & $0.675^{* *}$ & $0.277^{* *}$ & $0.244^{* *}$ & 1 & $0.443^{* *}$ \\
\hline Poor Social Support & $-0.384^{* *}$ & $0.518^{* *}$ & $0.577^{* *}$ & $0.150^{* *}$ & $0.443^{* *}$ & 1 \\
\hline Mean & 3.91 & 3.09 & 3.07 & 3.27 & 3.52 & 3.57 \\
\hline SD & 0.86 & 0.76 & 0.74 & 0.81 & 0.84 & 0.85 \\
\hline
\end{tabular}

**. Correlation is significant at the 0.01 level (2-tailed)

*. Correlation is significant at the 0.05 level (2-tailed) 
Table 3 shows that job satisfaction is negatively related to role conflict (RCO), job overload (JOV), poor social support (PSS), poor physical work environment (PPE), and role ambiguity (RAB). Table 3 further revealed that except for role ambiguity, other work stressors (role conflict, job overload, poor social support, and poor environment) investigated have a significant relationship with job satisfaction (JSN). Job satisfaction has a mean score of 3.91. This indicates showed that the respondents strongly agreed with the items used to measure the construct. Similarly, the majority of the respondents agreed with the items used in measuring the independent variables as their values are greater than the mid-point of 3.00.

To determine the dimensions of work stressors that impact job satisfaction, regression analysis was carried out. The results are shown in Table 4.

\section{Relationship between Work Stress and Job Satisfaction}

Table 4. Regression Analysis for Work Stressors and Job Satisfaction

\begin{tabular}{lllll}
\hline \hline Variable & \multicolumn{2}{c}{ Coefficient Std. Error } & t-Statistic & Prob. \\
\hline \hline C & 1.174653 & 0.302003 & 3.889543 & 0.0001 \\
PPE & -0.152450 & 0.065785 & -2.317397 & 0.0212 \\
JOV & -0.376931 & 0.068131 & -5.532430 & 0.0000 \\
PSS & -0.255415 & 0.084975 & -3.005766 & 0.0029 \\
RAB & -0.086813 & 0.052146 & -1.664807 & 0.0970 \\
RCO & -0.235718 & 0.064442 & -3.657817 & 0.0003 \\
\hline \hline R-squared & 0.363691 & Mean dependent var & 3.403974 \\
Adjusted R-squared & 0.352942 & S.D. dependent var & 1.268996 \\
S.E. of regression & 1.020779 & Akaike info criterion & 2.898676 \\
Sum squared residual & 308.4288 & Schwarz criterion & 2.972393 \\
Log-likelihood & -431.7001 & Hannan-Quinn criter. & 2.928171 \\
F-statistic & 33.83651 & Durbin-Watson stat & 2.355295 \\
Prob(F-statistic) & 0.000000 & & & \\
\hline \hline
\end{tabular}

The results in Table 4 indicated that the R-squared and Adjusted Rsquared were 0.363691 and 0.352942 respectively when the explanatory variables (role conflict, job overload, poor social support, poor physical environment, and role ambiguity) were regressed on job 
satisfaction of nurses (JSN). By implication, the independent variables, which are role conflict, job overload, poor social support, poor physical environment, and role ambiguity jointly explain $35 \%$ of the systematic variation in the dependent variable. Durbin-Watson of 2.355295 indicates that there is no serial autocorrelation in the regression results. Specifically, the results in Table 4 indicated that except for role ambiguity $(\mathrm{t}=-1.664807, \rho<0.05)$, all other work stressors investigated, that is, role conflict $(t=-3.657817, \rho<0.05)$, job overload $(t=-5.532430, \rho<0.05)$, poor social support $(t=-3.005766$, $\rho<0.05)$, and poor physical environment $(t=-2.317397, \rho<0.05)$ have a significant and negative relationship with job satisfaction. While role ambiguity has a negative relationship with job satisfaction $(\mathrm{t}=$ $1.664807, \rho<0.05)$, the relationship is however not significant. Given the results, as shown in Table 3 and Table 4, it can be deduced that except for role ambiguity, the work stressors investigated, that is, role conflict, job overload, poor social support, and poor physical environment are significant predictors of job satisfaction among nurses in public hospitals in Benin City, Edo State, Nigeria.

\section{Discussion}

The study revealed that job overload has a significant and negative relationship with job satisfaction. This is somewhat consistent with the study of Yaacob and Long (2015) who found that job overload is a significant predictor of job satisfaction. The findings of this study also confirm the results of Gulavani and Shinde (2014) that revealed that workload is a predictor of employees' job satisfaction. In alignment with these studies, Rita, Atindanbila, Portia and Abepuoring (2013) posited that work overload induced job dissatisfaction among employees considerably through depression, psychosomatic complaints, and irritations, which are associated with it.

The study further revealed that there is a significant and negative relationship between role conflict and job satisfaction among nurses in public hospitals in Benin City, Edo State, Nigeria. This is consistent with the study of Radhakrishnan (2013) that revealed that job satisfaction decreases with an increase in role conflict particularly 
when employees are given two or more incompatible roles to perform at the same time by different supervisors. The findings of this study also aligned with that of Ekienabor (2016) which showed that the incompatibility of expectations and demands associated with the role can make employees confused, dissatisfied, and increase their boredom. It also confirms the study of Gulavani and Shinde (2014) who revealed that conflict with doctors, supervisors, and peers is significantly associated with job dissatisfaction among nurses.

This study showed that poor physical environment has a significant negative influence on job satisfaction of nurses in public hospitals in Benin City. This finding is somewhat consistent with Ojekou and Dorothy (2015) that revealed that work-settings significantly influence mental health and wellbeing among student nurses in Nigeria. The results also align with those of Gupta et al. (2011) which revealed that constant interruptions from noisy colleagues, telephones, machines, and people moving up and down in hospitals because of the non-availability of comfortable chairs for patients to wait for doctors induce stress and, invariably, job dissatisfaction. Consistent with these findings, Ogungbamila (2013) suggested that noise, temperature, heat, pollutions, work safety conditions, and poor lightings are sources of strain, which contribute to low job satisfaction. Ogungbamila (2013) further noted that occasioned by the epileptic power supply and decaying infrastructural facilities, poor physical work environment in most public hospitals in Nigeria are associated with low morale among health care workers and could have detrimental effects on the wellbeing of employees.

The results of this study also revealed that poor social support has a significant negative influence on job satisfaction among nurses in public hospitals in Benin City. The results confirm the findings of Sinha, Chatterjee and Iskanius (2011) that increase emotional and instrumental support from supervisors reduce stress among employees and its consequences inspires job satisfaction, wellbeing, and turnover intentions. The findings of this study further confirm Adegoke (2014) observation that social support from superiors and co-workers reduce the level of role conflict among employees. In agreement with Beh and Loo (2012), the absence of social support will result in job dissatisfaction. The study further revealed a 
negative but insignificant relationship between role ambiguity and job satisfaction among nurses. The result deviates from several studies that found a significant negative relationship between role ambiguity and job satisfaction (Palomino \& Frezatti, 2016; Yaacob \& Long, 2015; Gulavani \& Shinde, 2014).

\section{Conclusions and Recommendations}

This study set out to investigate the relationship between work stress and job satisfaction among nurses in public hospitals in Benin City, Edo State, Nigeria. Based on the results obtained in the study, it was concluded that role conflict, job overload, poor social support, and poor work environment are the key predictors of job satisfaction among nurses in public hospitals in Edo State and Nigeria in general.

Based on the findings of this study, the following recommendations for policy-making are made.

1. Management of public hospitals in Benin City should employ more nurses as well as appraise the capacity of existing nurses in line with available equipment to know the number of patients the nurses can attend to per minute, hours, or in a day. Besides, the employment of more nurses will help reduce the patients/workload assigned to an existing nurse at a time, increase their time to do a good job, and reduce pressure to complete work activities that are associated with the highstress levels and job satisfaction among nurses.

2. Management of public hospitals in Benin City should reduce the level of role conflict experienced by nurses by ensuring that work activities provided for nurses are within the realm of their professions and personal convictions. Also, role conflict among nurses and subsequently high-stress levels can be minimized by ensuring the assignment of a patient and the administration of drugs (treatment) to one particular nurse at a time. Moreover, the management of public hospitals in Benin City can reduce the level of role conflict and subsequently high-stress levels by not giving nurses multiple conflicting work activities at the 
same time. Besides eliminating assignment of two or more job activities that are not compatible, management of public hospitals in Benin City can also reduce role conflict and subsequent high-stress level experienced by nurses by ensuring that individual nurse reports to one supervisor at any particular point in time rather than multiple supervisors.

3. Management of public hospitals in Benin City should ensure that the physical work environment is conducive for nurses to perform their duties. This can be done by ensuring thorough cleaning of public hospitals using antibiotic deodorant detergent as well as ensuring that the architectural design of the offices is appealing, intuitive, logical, and attractive and feature air ventilation mechanisms to reduce hot temperature often experienced by nurses. It can also be achieved by using solar power to generate light in the hospital rather than relying on plants (generators) and power generating companies who oftentimes provide epileptic electricity. Besides, the management of public hospitals in Benin City should expand the wards, offices, and other areas where patients receive treatment.

\section{References}

Adegoke, T. G. (2014). Effects of occupational stress on psychological well-being of police employees in Ibadan metropolis, Nigeria. African Research Review, 8(1), 302-320. https://doi.org/10.4314/afrrev.v8i1.19

Beh, L. S., \& Loo, L. H. (2012). Job stress and coping mechanisms among nursing staff in public health services. International Journal of Academic Research in Business and Social Sciences, 2(7), 131.

Bokti, N. L. M., \& Talib, M. A. (2009). A preliminary study on occupational stress and job satisfaction among male navy personnel at a naval base in Lumut, Malaysia. The Journal of International Social Research, 2(9), 299-307. 
Ekienabor E. E. (2016). Impact of job stress on employees' productivity and commitment. International Journal for Research in Business, Management and Accounting, 5(3), 56-63.

Essiam, J. O., Mensah, M. E., Kudu, L. K., \& Gyamfi, G. D. (2015). Influence of job stress on job satisfaction among university staff: Analytical evidence from a public university in Ghana. International Journal of Economics, Commerce and Management, 3(2), 1-15.

Folkman, S., \& Lazarus, R. S. (1984). Stress, appraisal, and coping (pp. 150-153). New York: Springer Publishing Company.

Gulavani, A., \& Shinde, M. (2014). Occupational stress and job satisfaction among nurses. International Journal of Science and Research (IJSR), 3(4), 733-740.

Gupta, M., Gupta, R., Mishra, S. C., \& Sharma, S. (2011). An examination of the relationship between academic stress and academic achievement in secondary classes students of Meerut. VSRD Technical \& Nontechnical Journal, 2(7), 320-325.

Hans, A., Mubeen, S. A., Khan, S., \& Al Saadi, A. S. M. (2014). A study on work stress and job satisfaction among headmasters: A case study of bilingual schools in Sultanate of OmanMuscat. Journal of Sociological Research, 5(1), 40. https://doi.org/ 10.5296/jsr.v5i1.5426

Hobfoll, S. E. (1989). Conservation of resources: A new attempt at conceptualizing stress. American Psychologist, 44(3), 513. https://doi.org/10.1037/0003-066x.44.3.513

Kadiri, A.P., \& Akinmayowa, J.T. (2015). Sources of stress among academics in a tertiary institution in Benin City. Management Science Review, 6(1\&2), pp. 99-120.

Locke, E. A. (1976). The nature and causes of job satisfaction. Handbook of industrial and organizational psychology. Chicago: RandMc Narlly. 
Macdonald, S., \& Maclntyre, P. (1997). The generic job satisfaction scale: Scale development and its correlates. Employee Assistance Quarterly, 13(2), 1-16. https://doi.org/10.1300/j022v13n02_01

Mardhiah, Y., \& Choi, S. L. (2015). Role of occupational stress on job satisfaction. Mediterranean Journal of Social Sciences, 6(2), 8187. https://doi.org/10.5901/mjss.2015.v6n2s1p81

Mathew, N. A. (2013). Effect of stress on job satisfaction among nurses in central Kerala. Journal of Business and Management, 7(2), 47-51. https://doi.org/10.9790/487x0724751

Ogungbamila, B. (2013). Occupational burnout among employees in some service occupations in Nigeria: Are health workers different? Psychological Thought, 6(1), 153-165.

Ogungbamila, B., \& Fajemirokun, I. (2016). Job stress and police burnout: Moderating roles of gender and marital status. IAFOR Journal of Psychology and the Behavioural Sciences, 2(3), 17-32. https://doi.org/ 10.22492/ijpbs.2.3.02

Ojekou, G. P., \& Dorothy, O. T. (2015). Effect of work environment on level of work stress and burnout among nurses in a teaching hospital in Nigeria. Open Journal of Nursing, 5(10), 948-955. https://doi.org/10.4236/ojn.2015.510100.

Palomino, M. N., \& Frezatti, F. (2016). Role conflict, role ambiguity and job satisfaction: Perceptions of the Brazilian controllers. Revista de Administração (São Paulo), 51(2), 165181. https://doi.org/10.5700/rausp1232.

Radhakrishnan, R. (2013). A study on impact of work stress among tile factory workers in Trichur district in Kerala. International Journal of Scientific and Research Publications, 3, 1-13.

Rita, A. A., Atindanbila, S., Portia, M., \& Abepuoring, P. (2013). The causes of stress and job satisfaction among nurses at ridge and Pantang hospitals In Ghana. International Journal of Asian 
Social Science, 3(3), 762-771.

Siddique, U., \& Farooqi, Y. A. (2014). Investigating the relationship between occupational stress, motivation and job satisfaction among university teachers (A Case of University of Gujrat). International Journal of Academic Research in Progressive Education and Development, 3(4), 36-46. https://doi.org/10.6007/ijarped/v3-i4/965

Sinha, T. R., Chatterjee, D., \& Iskanius, P. (2011). Measuring stress among hospital nurses: An empirical study using fuzzy evaluation. International Journal of Logistics Economics and Globalisation, 3(2-3), 142-154. https://doi.org/10.1504/ijleg.2011.042284

Spector, P. E. (1997). Job satisfaction: Application, assessment, causes, and consequences (Vol. 3). Sage Publications. https://doi.org/10.4135/9781452231549

Venkataraman, P. S., \& Ganapathi, R. (2013). A study of job stress on job satisfaction among the employees of small-scale industries. IOSR Journal of Business and Management (IOSRJBM), 13(3), 18-22. https://doi.org/10.9790/487x-1331822

Yaacob, M., \& Long, C. S. (2015). Role of occupational stress on job satisfaction. Mediterranean Journal of Social Sciences, 6(2 S1), 81. https://doi.org/10.5901/mjss.2015.v6n2s1p81

Yamane, T. (1967). Statistics: An introductory analysis. New York: Harper \& Row. 